\title{
A QUESTÃO DA ARTE E DA EDUCAÇÃO NA CIBERCULTURA
}

\author{
Isabella Fernanda Ferreira_(1)
}

Resumo: Sabendo que a expressão artística no ciberespaço é redimensionada consolidando a concretização do hipertexto, as questões sobre as quais se reflete neste artigo são: se a produção coletiva de uma "expressão" artística seria realmente condição para a sua universalidade, se além da multidimensionalidade no universo virtual não ocorreria também a unidimensionalidade, e por fim, possiveis conseqüências sobre a arte e a formação cultural.

Com a nova realidade da cibercultura, assistimos a uma adequação das formas estéticas, pois o grande artista do século XXI é aquele que providencia as virtualidades, na medida que arquiteta os espaços de comunicação, organiza os instrumentos coletivos da cognição e também da memória e, por fim, aquele que juntamente com o universo dos dados estrutura a interação sensório-motora. Como exemplos desses grandes artistas, podemos citar, Tim Berners Lee e todos os programadores inventores da World Wide Web, como também, os criadores de videogames, os inventores de programas para trabalho cooperativo e etc, podendo ser considerados como verdadeiros "engenheiros do mundo", segundo Lévy (1999).

A cibercultura não substitui com suas manifestações artísticas, a memória das culturas antigas, assim como o cinema não substitui o teatro, mas apresenta-se como uma outra forma original. Assim também ocorre com os gêneros emergentes da cibercultura como, por exemplo, a música tecno. Ao analisarmos a arte presente no ciberespaço, devemos salientar as suas especificidades, mas não generalizá-las para outras formas de arte. Como exemplos destas especificidades, podemos apontar, o declínio da figura do autor e, portanto, também, o declínio da gravação.

A obra artística interativa realizada no ciberespaço implica necessariamente uma experimentação, ou seja, os indivíduos que efetuam esta interação participam ativamente na estruturação da mensagem que recebem, portanto, as obras artísticas tornam-se criações coletivas, caracterizando-se como obras-fluxo, obrasprocesso. Obras, enfim, que não possuem um caráter de armazenamento, isto é, de conservação, pois no ciberespaço, as obras da cibercultura não possuem nítidos limites, ou seja, são obras artísticas consideradas "abertas", na medida que permitem uma multiplicidade de interpretações e também acolhem uma imersão ativa do explorador. São materialmente interpenetradas por outras obras de rede. Faz-se evidente, que o grau dessa "abertura", varia, em virtude do quanto são exploradas as possibilidades oferecidas tanto pela interação, pelos criativos dispositivos coletivos e também pela presença da interconexão, afastando-se assim, cada vez mais a obra de seu sentido clássico ao aproximar-se da típica obra da cibercultura (Lévy, 1999). 
Os adeptos desta expressão artística defendem que não há necessidade da existência de um autor para que uma obra artística seja grande, mesmo porque a construção da idéia de autor é algo recente na nossa história. Nas sociedades em que a palavra era a via de transmissão dos conteúdos culturais, a idéia de autor era quase que inexistente, sendo este considerado apenas como um intérprete capaz de distinguir e bem apresentar os textos. Com o surgimento da escrita, a concepção do que seria um autor, conquistou um pequeno espaço, porém, até o final da Idade Média não era qualquer indivíduo que, ao escrever um texto, poderia ser considerado um autor, mas tão somente aqueles "vestidos de uma autoridade", como o caso, por exemplo, de Aristóteles. Mais tarde com o surgimento da imprensa, a noção de autor passa a ser afirmada socialmente, pois, com a reprodução industrializada dos textos, tornou-se uma necessidade a definição do estatuto jurídico e econômico dos redatores (Lévy, 1999).

Uma leitura que pode ser efetuada, no que concerne à cibercultura, segundo Lévy (1999), é que toda a sua produção artística, atinge uma forma de universalidade, por meio da sua onipresença na rede. Este caráter de universalidade desencadeia o fenômeno que podemos denominar de destotalização. $\mathrm{O}$ avanço da destotalização ocorre em virtude do declínio de dois fatores: o autor (que causa o fechamento de sentido) e a gravação (que causa o fechamento físico e temporal da obra), pois o autor garante a possibilidade de um estável sentido. Mesmo se uma obra tivesse como pretensão uma significação aberta ou múltipla, ainda assim devemos pressupor um autor, se tivermos como objetivo, a interpretação de intenções, a decodificação de um projeto, uma expressão social ou mesmo inconsciente. A gravação funciona como um arquivo para a conservação da obra e faz desta, uma mensagem acabada.

Após a explicitação dos conceitos de autor e gravação, faz-se importante analisarmos como se desencadeia o processo de declínio desses conceitos no processo da cibercultura. A obra artística da cibercultura $3 / 4$ por apresentar-se metamórfica, ou seja, atravessada, conectada, indefinidamente co-construída $3 / 4$ dificilmente pode ser gravada justamente por possuir um caráter de constante transformação. Contribui, assim, para a destituição do autor como fiador de suas prerrogativas de sentido. Podemos concluir, então, que a obra de arte no ciberespaço encobre os dois fatores clássicos da totalização.

Por meio, tanto da interação como da imersão, o receptor da realidade virtual obtém a possibilidade de alcançar a obra, ou seja, participar dela, transformandoa, sendo em parte seu autor. Este fato coopera para o declínio da totalização, fazendo emergir o universal que pode, nesta leitura, ser definido como a possibilidade de todos banharem-se no mesmo rio de informações, ou seja, a possibilidade de todos terem acesso a uma mesma fonte, disponibilizada por meio da dinâmica da interconexão da hipermídia on-line, da divisão informacional, da ubiqüidade do virtual inserido nas redes que a transporta (Lévy, 1999).

Frente a esta leitura até então tecida, a reflexão que se torna pertinente é a de tentar questionar se uma expressão artística, (como é a presente no ciberespaço com o hipertexto e suas diferentes manifestações), torna-se universal simplesmente 
pelo fato de ser acessível coletivamente. Será que este tipo de interpretação não reduz o verdadeiro caráter universal de uma obra-de-arte? Porém, tal questionamento não é sinônimo de uma tentativa de afirmar que na cibercultura não possam ocorrer expressões artísticas universais, mas sim, de refletir sobre a verdadeira condição para que uma expressão artística carregue a sua marca de universalidade, que talvez não estaria tão somente no fato desta ser acessível e coletivamente produzida.

Atualmente, o que se tem como pressuposto é a substituição da arte individualista pelas artes de formas coletivistas, nas quais a arte, em virtude do seu relacionamento com o coletivismo e o individualismo, enfrenta o que Adorno, em seu artigo Teses sobre religião e arte (2000) denominou de "beco sem saída", reflexo da crise da sociedade atual em si mesma. Esta presente crise que envolve tanto a individualidade como as tendências coletivas de nossa sociedade, não é motivo substancial que, por si mesmo, justifique o retrocesso da arte a um estágio anterior à era individualista, como, por exemplo, submeter-se novamente às amarras da religiosidade.

Esta sociedade atual em crise está repleta de antagonismos grupais, e é também altamente discriminatória. Nela, tanto a religião positiva como a filosofia tradicional perdem seu caráter de atração às massas, o que torna atrativa a idéia para muitos, de um arte que efetue o papel de integração exercido anteriormente pela filosofia $e$ pela religião.

Nesta concepção de arte como força de integração, esta deveria transmitir mensagens em prol da solidariedade, fraternidade, igualdade e etc. A universalidade em questão, porém, no que diz respeito ao valor destas idéias, a sua verdade inerente, somente pode ser considerada por meio de um pensamento filosófico autônomo, portanto, sem aplicação social propagado pela arte, pois o que se pode ocorrer são as idéias filosóficas transformarem-se em slogans, e meras imagens sensuais, pois a identidade tanto da arte como da religião e da filosofia, mesmo que verdadeira é frágil por ser abstrata, Adorno (2000).

O que existe na realidade desta maneira, é uma identificação, uma reconciliação como forma de "bens culturais", bens que se tornam na sociedade inofensivos e importantes, desencadeando uma aparente ênfase humanista, que se torna mera ideologia. A arte, que tinha como finalidade preencher seu destino humano, não pode se tornar humana e nem proferir palavras humanistas, em virtude desses bens culturais serem reduzidos a algo comumente aceitável dentro de um padrão conformista, de uma já dada cultura que gera uma aparência ilusória de identidade espiritual e, rompe com o que na arte é mais característico de sua essência: o fato de ser força de protesto humano contra qualquer tipo de opressão das instituições dominantes.

Esta arte como força de integração social, e portanto, mera ideologia, tem no conceito de universalidade, (no caso específico das expressões artísticas da cibercultura), uma mentira, pois prega sua obtenção tão somente pela fácil acessibilidade e por sua produção coletiva, o que na realidade não é condição 
pois, a relação de uma obra de arte com a universalidade é estabelecida de maneira não direta, o que nos permite evidenciar a verdadeira natureza da obra de arte, que carrega na sua micro expressão, a presença do macro quando atinge o apogeu de sua genuína individualização $e$, se torna verdadeiramente portadora do universal.

A universalidade é concretizada quando a arte, apesar de pertencer a um tempo específico, é reapropriada, reinterpretada em outros tempos, por outros inúmeros indivíduos, que darão novos sentidos a algo que já detinha um sentido. Estes sentidos se perpetuam, fazendo da obra de arte eterna, aberta, universal apesar de única, Adorno (1988).

Segundo os defensores da estrutura atual do hipertexto, a sua universalidade $3 / 4$ gerada pela onipresença destas expressões na rede, que na verdade não é condição suficiente para sua universalidade $3 / 4$ causa o fenômeno da destotalização da arte que permite a esta, seu caráter de fechamento de sentido e da gravação, ou se preferirmos, seu caráter de conservação (causador do fechamento físico $e$ temporal da obra de arte). Contudo, a figura do autor não é necessariamente sinônimo de fechamento de sentido, pois a obra fornece a possibilidade de uma reinterpretação por parte de quem as absorve, e, no que concerne ao caráter de conservação, ou de gravação, esta não causa o fechamento físico e temporal de uma obra de arte, mas tão somente marca a sua autenticidade, a sua singularidade, a sua originalidade advinda do momento da sua produção, não se fechando de forma alguma, pois carrega a possibilidade de ser absorvida em outros tempos, situação esta que oferece à obra o verdadeiro sentido da sua universalidade.

Podemos questionar se o declínio do autor e da gravação como "frutos" de uma universalidade gerada pela acessibilidade e produção coletivas, não seriam ao contrário, "fruto" de uma ausência de universalidade, pois pode ocorrer a perda do conteúdo da sua autenticidade, que necessariamente deveria estar enraizada em uma tradição que representa o aqui e o agora da sua originalidade, ou seja, a sua única existência, a razão que permite a sua reconstrução histórica e com ela todas as reinterpretações possíveis que a perpetuam, universalizando-a. Contudo é importante que fique claro que o fato de uma obra de arte ser coletivamente produzida e acessível não é condição para esta tornar-se universal, nem para que não seja.

Com esta crescente coletivização da produção da expressão artística, contemplamos a presença de um homem multidimensional, ou seja, aquele que por meio do ciberespaço consegue se fazer onipresente, porém, inserindo esta situação no contexto social ao qual estamos vivendo, percebemos que mesmo em diferentes locais, o homem atual encontra uma enorme dificuldade para expressarse também diferentemente. Dificuldade esta promovida por uma maneira de pensar denominada por Marcuse (1973) de unidimensionalizada.

Com a presença das expressões artísticas da cibercultura, assistimos a um grande discurso otimista de louvação à liberdade proporcionada por tal obra de arte, 
graças à sofisticação das tecnologias informáticas nesta era da sociedade industrial moderna. Porém, a questão a ser refletida é se realmente ocorre a total liberdade na realidade da multidimensionalidade.

Pierre Lévy (1999), como um desses autores considerados otimistas perante as novas tecnologias, critica muitos pensadores que analisam as tecnologias como força bélica, ou seja, como se a tecnologia fosse um projétil cujo alvo seria a sociedade e a sua cultura. Este pensamento, segundo ele, não esclarece adequadamente a leitura dos fenômenos produzidos com essas tecnologias. Sua interpretação vai justamente em posição contrária, pois contempla as técnicas como imaginações, fabricações e reinterpretações realizadas pelos homens. $\mathrm{O}$ mundo é visto como simultaneamente humano e técnico, pois fica impossível separar o ser humano do seu ambiente material, do mesmo modo que, não se pode separar do mundo material as idéias humanas que estão na sua materialidade, pois as técnicas carregam imanentes a si mesmas uma variedade de projetos e imaginações humanas, como também implicações sociais e culturais que não nos permitem analisar os efeitos da técnica em um sentido generalizante, como Lévy (1999) afirma que fizeram os discípulos de Heidegger ou os frankfurtianos.

Ainda na visão de Lévy, não daria para colocar em um mesmo plano, por exemplo, a eletrônica e a energia nuclear. A realidade é que, por traz de toda técnica, agem e reagem idéias, o que não permite um único sentido à técnica. Essas idéias, projetos de caráter heterogêneo, causam um conflito de objetivos que se alimentam e se reforçam mutuamente, desencadeando uma grande desestabilidade, que torna muito difícil a análise das implicações sociais e culturais da informática, principalmente pelo ritmo acelerado das transformações do universo digital.

Porém, como não se tornar insensível frente aos inúmeros "impactos" gerados pela técnica, ou melhor dizendo, pela racionalidade irracional que a rege, quando estes "impactos" podem ser anunciados como a dominação do homem pelo próprio homem, como a produção do que Adorno (1995) denomina de "tendências de regressão".

Lembremos que hoje pessoas com traços sádicos reprimidos são criadas constantemente por toda parte por uma geral tendência social, quando em cada situação o indivíduo tem a sua consciência mutilada, que por sua vez é refletida diretamente no seu corpo de modo não-livre, proporcionando um ambiente favorável para a violência, à situação fica muito mais complexa.

O que por um lado, representa a identificação cega do indivíduo com o coletivo que converte a si mesmo num material desprovido de capacidade de autodeterminação, dotado de uma consciência coisificada, sendo coisa e fazendo também do outro coisa e, por outro lado, a manipulação torna o indivíduo incapaz de levar a cabo experiências humanas direta, em virtude, da ausência de emoções por um exagerado realismo $3 / 4$ o que justifica o uso da técnica para a concretização de acontecimentos desumanos, como guerras mundiais, a fome, uma Hiroshima e Nagasaki, a existência de Campos de Concentração?!!! A falta de sensibilidade 
frente à possibilidade destes "inúmeros" impactos, ou até mesmos aqueles mais "sutis" como a perpetuação oculta de uma racionalidade irracional, é a condição perfeita para que tamanhos feitos sejam possivelmente gerados.

Marcuse (1973) afirma que a realidade social hoje é a dominação do homem pelo próprio homem, que advêm da união do que ele denominou de Razão prétecnológica e Razão tecnológica, ambos "frutos" de uma história contínua que resulta na moderna sociedade contemporânea, que almeja a mudança tecnológica da natureza, pois é por meio desta transformação, que ocorre uma alteração na base da dominação desta sociedade. A sociedade agora instala-se por meio de uma dependência, que se submete à "ordem objetiva das coisas", isto é, dependência das leis de mercado, leis econômicas, etc. O resultado é uma sociedade que embora modificada não altera a sua estrutura hierárquica, explorando com enorme eficiência os recursos tanto naturais como mentais. Esta dominação é gerada por uma alta racionalidade, cujos limites estão enraizados justamente na progressiva escravização do homem, realizada por um aparato produtor altamente nocivo a todos aqueles que o constrói e utiliza.

Um aparato que carrega uma ambigüidade de características, pois se de um lado, tem como objetivo final à criação de uma existência mais humana baseada, portanto, em uma realidade fornecedora de um mais elevado padrão de vida, por outro lado, esse mesmo aparato técnico, destrói este mesmo objetivo, carregando, desta forma, inicialmente o negativo que se encontra no positivo, ou seja, o desumano que se aloja na humanização, a escravização que se aloja na libertação.

Faz-se importante salientar que o homem que é capaz de estar em vários lugares "ao mesmo tempo" e que, deste modo, pode ser caracterizado como universal, ou seja, multidimensional, também pode ser conhecido como unidimensional, pois "contaminado" pela racionalidade irracional presente na sociedade, veicula multidimensionalmente modos de agir e pensar únicos, "intoxicando" esse aparato técnico que é o computador.

Estamos diante de uma nova dialética: ao mesmo tempo em que este indivíduo é multidimensional, ele também é unidimensional. Ser consciente da presença desta dialética é usar uma tecnologia sabendo que ela possui uma carga ideológica, é posicionar-se criticamente frente a esta unidimensionalidade, tendo como possibilidade à criação nestas redes virtuais de "focos de resistência".

Neste contexto de unidimensionalidade, ou seja, de criação e promulgação de uma maneira única de agir e de se comportar, gerado no seio da sociedade industrial moderna (especificamente a mais avançada), qual seria a conseqüência direta desta sobre as obras artísticas que, produzidas agora, são "infectadas" mais do que nunca com esse caráter unidimensional na era da reprodutibilidade técnica?

A questão central é que para essas obras serem objetivadas, e desse modo, possam ser expostas, apresentadas, ou seja, democratizadas, elas passam por momentos de coerção ora explícitas ora mais sutis. Sutis quando o artista no momento da produção de sua arte, sem ser consciente disso, já possui tão bem internalizada a 
lógica da indústria cultural semiformadora, que produz sem mesmo perceber uma obra-de-arte, estandardizada, padronizada.

O outro momento de constrangimento à produção da obra-de-arte é quando o artista, que tem na sua arte um trabalho profissional, como meio de sobrevivência, ou seja, um artista que depende da renda de seu trabalho ou optou por isto, termina na maioria das vezes, contra a sua própria vontade, vendendo-se à padronização da Indústria Cultural porque somente assim terá seu trabalho vendido. Um bom exemplo disso no Brasil é que os melhores instrumentistas tocam e fazem os arranjos das famosíssimas duplas sertanejas, e etc, permanecendo no anonimato, sabendo que seus trabalhos alternativos não serão facilmente divulgados e, não lhes darão o lucro que eles obtêm quando estão diretamente trabalhando para a indústria da produção cultural.

Mas o constrangimento à obra-de-arte, não se restringe tão somente ao seu momento da produção, ele também ocorre no momento da contemplação, porque as pessoas já associaram tanto a arte como tão somente diversão e entretenimento, que ao contemplarem, ao ouvirem, ao lerem uma obra-de-arte, já sofreram uma regressão de seus sentidos e, de sua capacidade de reflexão que o elemento mimético de uma obra-de-arte pode estimular, perdendo a oportunidade, tanto de um autoconhecimento, como do conhecimento do "mundo" que o circunda (Adorno, 1988).

A verdadeira arte só sobrevive como algo que faz parte da sua própria definição e, não como algo externo a si mesma, isto é, embora não se referindo à sociedade, a fórmula kantiana de "finalidade sem fim", permite-nos verificar que a ausência de finalidade da arte, é condição para que esta escape da coerção da autopreservação, pois ela consegue incorporar algo de livre no seio da não liberdade.

Nesta condição, sua própria existência a coloca em um caminho inverso ao da dominação, que já é em si, uma promessa de felicidade expressa em meio ao desespero. Esta "promessa" de felicidade é o que constitui sua alegria e não o entretenimento, a diversão, o espetáculo fornecido pela indústria da produção cultural. Desse modo, o alegre na arte é o contrário do que muitas vezes assumimos levianamente como tal, pois não se trata do conteúdo em si, mas, sobretudo do seu procedimento, do abstrato que permite à arte abrir-se à realidade, ao mesmo tempo em que denuncia a violência. Eis aí, tanto a alegria como a seriedade da arte, na medida que, ela é capaz de modificar a consciência existente, tornando-se um meio para a obtenção do conhecimento.

Porém, a relação entre o sério e o alegre da arte é submetida a uma dinâmica histórica, o que nos permite verificar que, com o advento da indústria cultural, a arte é colocada entre os bens de consumo, o que fez de sua alegria sintética, falsa $e$ enfeitiçada, graças à arbitrariedade da imposição, pois atualmente onde se contempla o divertido, contempla-se o imposto. Diante deste constrangimento a que a arte objetiva está submetida, quando na construção de algo artístico reduz seu resultado a um mero produto, é que se torna importante a análise da dialética 
da produção da obra-de-arte, que Benjamin (1993) nos traz no seu ensaio $A$ obra de arte na era de sua reprodutibilidade técnica, bem como da reflexão sobre a dialética da essência da obra-de-arte abordada por Adorno (1988) em sua obra Teoria Estética, quando descreve a tensão existente entre o elemento mimético e o elemento racional que são intrínsecos a uma verdadeira expressão artística.

Benjamin (1993), por meio de suas teses sobre as tendências evolutivas da arte nas atuais condições produtivas, mostra-nos o valor duplo das novas tecnologias de reprodução da obra-de-arte, pois, se de um lado, observa que a alteração da percepção visual ou auditiva representou perdas, como a da aura da obra-de-arte, por outro lado, avalia que as obras de arte foram democratizadas, permitindo inclusive, a contemplação de detalhes no mundo nunca antes imaginados por meio do que ele denominou como possibilidade da experiência do inconsciente ótico, ou seja, a técnica permitindo a contemplação de realidades que jamais os olhos humanos teriam condições para realizarem.

Percebe-se desta maneira, que no decorrer dos grandes períodos históricos, $e$ ainda mais, internamente a estes, coexistem mutações na percepção das coletividades humanas e também no seu modo de existência, inseridas nestas as convulsões sociais.

Tendo em vista a constatação desta transformação a que a percepção está sujeita, identificamos que os fatores sociais específicos que condicionam o declínio atual da aura estão intimamente ligados à crescente difusão $e$ intensificação dos movimentos de massa, que superam o caráter único de todos os fatos, por meio da sua reprodutibilidade, fenômeno que ocorre em virtude de uma nova forma de percepção, cuja característica fundamental está na capacidade de captar "o semelhante no mundo", por via da reprodutibilidade técnica, retirando o objeto do seu invólucro e destruindo sua aura, isto é, a sua singularidade.

Podemos assim questionar até que ponto a reprodução técnica seria considerada arte numa era em que a técnica deixa de ser intra-estética (sendo apenas um meio para a concretização de sua expressão), para se tornar extra-estética, (tornando-se a própria finalidade da sua expressão) (Adorno, 1988). Concepções diferentes, portanto, do que seria importante em uma obra de arte.

A questão sobre a qual refletimos aqui é: será que com esta mudança de concepção do que seria importante em uma obra de arte não se corre o risco da obra-de-arte ser comprometida em sua essência, ou seja, na sua expressão dialética que se fundamenta na tensão entre os elementos racionais e miméticos inerentes a ela, quando a técnica deixa de ser intra-estética para se consolidar como extra-estética?

Segundo Adorno (1988), a arte para conseguir expressar-se, ou seja, para conseguir alcançar aquela linguagem imediata que permite a expressão daquilo que nenhuma linguagem consegue expressar, esta necessita da tensão entre os elementos miméticos e racionais inerentes a ela. O elemento mimético permite ao indivíduo o encontro com o natural, com o encantamento, efetuando a 
apresentação do irracional, isto é, fornece a possibilidade da expressão do inconsciente, das sensações, dos sentimentos, do afeto que o artista consegue demonstrar, quando em contato com o natural, encontra por meio do elemento racional, ou seja, com o seu momento criador e organizador, ou até diria, de planejamento, a possibilidade de transformar em linguagem toda a sua irracionalidade.

Porém, para que esta linguagem se torne concreta, para tornar-se objetiva, faz-se necessária à presença da técnica como o meio para a consolidação da expressão racional do elemento irracional que é a mímeses. Na obra de arte verdadeiramente expressiva não existe nem a absolutização do elemento mimético e nem a absolutização do elemento racional, mas, uma tensão, uma coexistência, uma interligação, uma ocorrência de aspetos autônomos e adaptativos.

Tanto no momento da contemplação, como no instante da produção de uma obrade-arte, quando esta consegue expressar-se, estão presentes os elementos racionais e miméticos da obra.

No momento da contemplação, o indivíduo entra em contato com o elemento irracional do artista por meio da técnica que permitiu sua expressão e, ao entrar em contato com este elemento irracional, tem a possibilidade de transformar essa irracionalidade (quando efetua o exercício de reflexão) em autoconhecimento, pois neste exato momento houve o encontro do irracional do indivíduo contemplador com o irracional do artista, que gerou a reinterpretação daquela arte por parte do indivíduo apreciador, gerando um autoconhecimento ou um conhecimento de algo que o circunda.

No que diz respeito, ao instante da produção da obra-de-arte, o artista terá a possibilidade de transformar em linguagens, de expressar a sua irracionalidade, por meio da técnica que, quando utilizada, desencadeia um exercício racional ao questionar qual a melhor maneira de "dizer" o que o elemento irracional "fala".

Porém, atualmente na sociedade industrial moderna, o artista depara-se com a presença da dialética da técnica criada pela ideologia presente em uma tecnologia de espoliação. Isto é, a técnica pode ser, por um lado, intra-estética ajudando a arte como um meio para efetivar a sua expressão, ou, por outro lado, tornando-se extra-estética, ou seja, um fim em si mesma, desencadeando a plena integração da obra de arte no seio da indústria cultural, rompendo a tensão entre os elementos miméticos e os elementos racionais, destruindo sua dialeticidade, isto é, acabando com a sua possibilidade de expressão e gerando tão somente uma manifestação artística que é interpretada ilusoriamente pela sociedade como sendo expressão, mas na realidade é tão somente uma manifestação que não consegue se expressar.

Frente a tudo isto podemos ousar afirmar que quando uma arte consegue se expressar, ela por sua própria essência, que se baseia na reapropriação do irracional de maneira racional, já denuncia, isto é, já torna-se uma reação à má irracionalidade do mundo racional enquanto administrado, pois ela consegue apresentar como forma de conhecimento a obscuridade desta irracionalidade 
justificada como sendo racional, até mesmo quando cria a dominação do homem pelo próprio homem (Adorno, 1988).

Compreender a dialética da técnica gerada no âmago da sociedade industrial moderna (que relativiza a finalidade da obra artística, ou melhor dizendo, cria um fim para ela), é central para refletir sobre todas as obras artísticas existentes neste contexto histórico, inclusive o caso específico por nós levantado $3 / 4$ o hipertexto $3 / 4$ que pode ou não ter sua expressão comprometida, na medida que, ou ele se integra totalmente à coerção ideológica da indústria cultural, ou garante sua expressão pela presença da tensão entre os elementos miméticos e racionais.

Com a onipresença objetiva da indústria cultural, assistimos também à onipresença da semiformação que, segundo Adorno (1996) sedimenta uma cultura negativa, cuja origem e sentido sucedem à própria formação cultural, convertendo-se em alienação onipresente apesar de toda ilustração e informação difundida, tornandose nada mais que a contra-face subjetiva produzida pela face objetiva da indústria cultural, na qual, a única maneira de garantir a permanência viva da cultura atualmente seria a auto-reflexão crítica sobre a vigência da semicultura. Mediante estas constatações, Adorno (1996) em seu artigo Teoria da semicultura coloca a necessidade da permanência da tensão entre autonomia e adaptação, pois se esta se desfaz, instala-se na sociedade uma "hegemonia unilateral", ou seja, forma-se uma sociedade inteiramente adaptada provedora de uma formação regressiva.

Como parte integrante da cultura, a formação (Bildung) irá possuir as dimensões tanto da autonomia como da adaptação que no capitalismo liberal com a burguesia, efetuou a grande promessa de concretização de uma verdadeira cidadania universalizada, porém, de uma maneira perversa dada à predominância da dimensão adaptativa, ficou impossibilitado instaurar a concretização da proposta de uma sociedade livre e igualitária, acabando por gestar a indústria da produção cultural, absolutizando a formação cultural no seu momento de adaptação no capitalismo tardio quando os indivíduos são condicionados a não serem mais autônomos, não criticando, portanto, o existente e não se apropriando da cultura.

A proposta perante esta contextualização é a retomada da tensão entre o momento da adaptação e da autonomia, tendo como finalidade a adaptação dos homens, preparando-os para a realidade, mas também desenvolver neles a capacidade de serem autônomos, por meio da desconfiança, negatividade e resistência.

Em sua análise histórica, Adorno (1996) argumenta que com o surgimento da burguesia ocorreu uma emancipação da formação acompanhada de uma promessa de cidadania universalizada acima de tudo por meio da leitura e da escrita. Como a emancipação não ocorreu, gerou-se a semiformação, passando-se de uma heteronomia a outra. Dessa maneira, será que as denominadas "escritas coletivas" , como também todo o discurso sobre a educação à distância, também não funcionariam como uma promessa de universalização da cidadania, que inserida na realidade da indústria cultural corre o risco de também se converter em semiformação? 
Frente à problemática a que os sistemas educativos estão submetidos em virtude de uma crescente demanda pela formação, Lévy (1999) argumenta que não sendo possível o corpo docente atender a toda esta procura, faz-se necessário encontrar outras maneiras de resoluções para esta questão, como a utilização de técnicas que ampliariam o esforço, tanto dos professores como dos formandos.

Com esta nova relação do saber no ciberespaço, acredito que a postura menos injusta e, portanto, a mais adequada, seria a de relativizar todas estas questões, refletindo sobre a formação e também sobre o papel da educação na cibercultura que está inserida em uma sociedade atualmente administrada.

Frente às argumentações do otimista Lévy (1999), no que concerne ao uso do ciberespaço para o estabelecimento de um processo de ensino e aprendizado à distância, motivado por um saber coletivo e ainda mais, trazendo como possibilidade a criação de novos meios para o reconhecimento dos diversos saberes adquiridos pelos indivíduos, demandados pela sociedade capitalista, torna-se importante refletir que ocorre uma forte carga de preocupação com a dimensão adaptativa do processo formativo.

O que se leva muito em consideração em tal argumentação, é a capacidade que o indivíduo possui de poder permanecer integrado nesta atual sociedade industrial, tecnológica, globalizada. Para isso, a educação teria como sua principal função, em seus níveis sistemáticos e assistemáticos, construir um indivíduo que acompanhe, que se integre, enfim, que se adapte à racionalidade já implantada por essa mesma sociedade, para assim sobreviver "bem" neste mundo. Trata-se de acompanhar com eficiência as mudanças pelas quais a civilização está passando e, acima de tudo, atender com precisão a exigência profissional atual, interessado em um indivíduo capaz de saber fazer um "pouquinho de tudo", o que Lévy defende como sendo a presença de um saber-fluxo e não de saberes estáveis.

Contudo, o grande perigo de tal reflexão consiste em reduzir o processo formativo somente à sua dimensão adaptativa, trazendo o grande prejuízo de não se ter à possibilidade da concretização do verdadeiro ideal da formação, pois, uma vez que a dimensão adaptativa aniquila a possibilidade da autonomia, instaura-se nesse processo de ensino-aprendizagem, uma hegemonia unilateral, ou seja, o indivíduo torna-se meramente um "depósito" de informações que, ao invés de cooperar beneficamente para um real processo formativo, danifica-o ao concretizar uma heteronomia e não uma autonomia.

Além da preocupação com a adaptação do indivíduo nesta nova realidade que é o ciberespaço, faz-se necessária também uma reflexão sobre a possibilidade do exercício da autonomia manifestada por esse mesmo indivíduo frente a esta mesma realidade. Levando em consideração a dimensão da autonomia como parte integrante do processo formativo, outras questões não consideradas por Lévy têm necessariamente que ser analisadas com uma maior dedicação.

Há a necessidade de ser relativizar o discurso otimista, ou melhor dizendo, de se relativizar o slogan otimista que traz o ciberespaço como um novo espaço onde 
pode ser promovida a democratização do processo formativo como cidadania universalizada, por meio do fácil acesso de todos, podendo este "todo" usufruir desse novo universo informacional, pois, atualmente, ele ainda pode ser considerado pseudodemocrático, por dois principais motivos:

- Pela presença de uma desigual disseminação dos computadores, pois ainda é uma pequena parcela da sociedade que usufrui deste acesso, que significa nada mais que o reflexo de uma sociedade marcada pela desigualdade econômica, tendo em sua base a divisão de classes, que também por conseqüência gera uma hierarquia na sociedade informatizada. Há aqueles que possuem o acesso, os que não o possuem, aqueles que o possuem $e$ conseguem passar pela experiência formativa, e por fim, aqueles que têm acesso e não conseguem atingir realmente uma verdadeira experiência formativa.

- Pelo oceano de informações trazidas do ciberespaço ser ainda considerado como sinônimo de formação, o que já nega a própria possibilidade da experiência formativa com o auxílio da indústria cultural causadora de uma semiformação generalizada socialmente.

Com esta constatação de uma pseudodemocracia provocada pela cibercultura, a intenção central não é a de cair em um pessimismo fatal, mas, ao contrário, contemplar a possibilidade de uma verdadeira democratização desse processo formativo, porém, sem se deixar levar por uma reflexão ingênua desta realidade. Faz-se necessário lutar como educadores para concretizar, na medida do possível, uma experiência formativa que seja realmente vivenciada com plenitude $e$ autonomia nesse novo espaço que é o ciberespaço. Para isso, a própria educação dever ser transformada em espaço para o estabelecimento de uma reflexão crítica sobre a semiformação presente no ciberespaço.

\section{Referências}

ADORNO, T. W. A arte é alegre. In:__ Teoria Crítica,estética e educação. São Paulo/Piracicaba, SP: Autores Associados/Editora Unimep (apoio Fapesp), 2000.

ADORNO, T. W. Teses sobre religião e arte. In: Teoria Crítica,estética e educação. São Paulo/Piracicaba, SP: Autores Associados/Editora Unimep (apoio Fapesp), 2000.

ADORNO, T. W. Notas de literatura Rio de Janeiro, RJ: Tempo Brasileiro,1991.

ADORNO, T. W. Teoria da semicultura. Revista Educação e Sociedade, n ${ }^{\circ}$ 56, Ano XVII, 1996.

ADORNO, T. W. Educação e emancipação. Rio de Janeiro, RJ: Editora Paz e Terra, 1995.

ADORNO, T. W. Teoria Estética. Lisboa: Edições 70, 1988. 
BENJAMIN, W.Magia e Técnica, Arte e Cultura: ensaios sobreliteratura e história da cultura. Obras Escolhidas, v. 01. São Paulo, SP: Brasiliense, 1993.

CAMPOS, A. de. http://www.uol.com.br/augustodecampos.

FURASTÉ, P. A.Normas técnicas para o trabalho científico. Porto Alegre, RS:

Dáctilo - Plus, 2000.

GONSALVES, E. P. Iniciação à pesquisa científica. Campinas, SP: editora Alínea, 2001.

LÉVY, P. O que é o virtual. São Paulo, SP: Editora 34, 1996.

LÉVY, P. Cibercultura. São Paulo, SP: Editora 34, 1999.

MARCONDES, F. A linguagem da sedução. São Paulo, SP: Perspectiva, 1998.

MARCUSE, H.A ideologia da sociedade industrial: o homemunidimensional. Rio de Janeiro, RJ: Zahar, 1973.

RAMOS-DE-OLIVEIRA, N, ZUIN, A. A. S., PUCCI, B. Teoria Crítica,estética e educação. São Paulo/Piracicaba, SP: Autores Associados/Editora Unimep (apoio Fapesp), 2000.

SALDANHA, L. C. D.Escrita, leitura e saber na cibercultura e suasrelações com a educação . São Carlos, SP: P.P.G.E da UFSCar - Tese de Doutorado, 2001.

SEVERINO, A. J. Metodologia do trabalho científico. São Paulo, SP: Editora Cortez, 2002.

(1) Mestranda em Educação Escolar (UNESP). Foi bolsista de iniciação científica pelo CNPq. Projeto integrado de pesquisa incluindo as instituições: UFSCar, UNESP e UNIMEP com o eixo temático, Tecnologia, Cultura e Educação.

Orientadores: Drs. Newton Ramos-de-oliveira, Antônio Álvaro Soares Zuin e Bruno Pucci. Este artigo é uma síntese dessa pesquisa realizada. E-mail para contato:

bella_ff@ig.com.br 